histamine as well as other mediators released after antigenic stimulation of the mast cell could be implicated in the development of tissue damage in $H$ pylori positive patients. We think that histamine released by these or by other mechanisms could also be involved in gastric acid hypersecretion in these patients.

1 Queiroz DMM, Mendes EN, Rocha GA, Barbosa AJA, Carvalho AST, Cunha-Melo JR. Histamine concentration of gastric mucosa in Helicobacter pylori positive and negative children. Gut 1991;32:464-6.

2 Queiroz DMM, Mendes EN, Rocha GA, et al. Helicobacter pylori and gastric histamine concentrations. J Clin Pathol 1991;44:612-3.

3 Smith JTL, Pounder RE, Nwokolo CU, et al. Inappropriate hypergastrinemia in asymptomatic healthy subjects infected with Helicobacter pylori. Gut 1990;31:522-5.

4 Aceti A, Celestino D, Caferro M, et al. Basophilbound and serum immunoglobulin E directed against Helicobacter pylori in patients with chronic gastritis. Gastroenterology 1991;101: 131-7.

\section{Repair of fetal bodies after dissection}

We have, for the past year, used a method similar to that described by Gau and her colleagues to repair both fresh and formalin fixed fetal bodies after dissection, ${ }^{1}$ and occasionally to completely reconstruct early second trimester fetuses received in fragments after genetic termination of pregnancy by suction or other evacuation methods. We have found that large skin defects in the small fetus can be repaired using a patch of amnion attached with adhesive. Whether a single or double layered patch of amnion or a sheet of amniochorial membrane is used depends on the fetal skin colour, thickness, and texture in the region to be repaired. Moreover, we have found that colourless cyano acrylate adhesive, usually referred to as Super glue and commonly used to assemble plastic models and for domestic repairs, is entirely satisfactory and fully acceptable to funeral directors and parents. Even in single drop dispensing tubes this is between 10 and 20 times cheaper than surgical adhesive and is cheaper still in larger tubes.

C MOTT HM CHAMBERS Department of Pathology, Department of Pathology,
Adelaide Medical Centre for Women and Children,
Queen Victoria Hospital, Adelaide, Australia

1 Gau GS, Napier K, Bhundia J. Use of a tissue adhesive to repair fetal bodies after dissection. $J$ Clin Pathol 1991;44:759-60.

\section{Experience of invasive aspergillosis in Hong Kong}

We read with interest the article by Boon et $a l^{1}$, and would like to share our experience in Hong Kong.

We reviewed the records of the 2462 necropsies performed between 1987 and 1990 by the Department of Pathology, Queen Mary Hospital, Hong Kong. Using the same criteria as Boon et al, ${ }^{1} 11$ cases of invasive aspergillosis were identified (eight males and three females with a mean age of 46.4 years, ranging from 12 to 81 years). Eight of these were considered to be high risk for aspergillosis: they had haematological malignancies (four with acute myeloid leukaemia, two with chronic myeloid leukaemia in blastic transformation, one with acute lymphoblastic leukaemia and one with polycythaemia rubra vera). One patient was receiving long term total parenteral nutrition after extensive gut surgery. Another was a 78 year old man with an incidental finding of a $1 \mathrm{~cm}$ hepatocellular carcinoma at necropsy. The last case was a 12 year old girl with apparent good health who suddently developed bronchopneumonia and died four days later; necropsy showed invasive aspergillosis in both lungs. The commonest site of infection is the lung, evident in all our cases, and other sites include the liver, spleen, kidneys and the heart.

Invasive aspergillosis was not diagnosed until necropsy in all our 11 cases, although fungal infection was strongly suspected in three of them. Repeated cultures for aspergillus were negative and transbronchial biopsy specimens were taken in the three cases, but none was considered diagnostic of aspergillosis.

Boon et al commented that invasive aspergillosis is not exclusive to the classic "high risk" group and included three in their report. ${ }^{1}$ There were also three such cases in our series, although two of the patients were debilitated by total parenteral nutrition or solid malignancy while the young girl was apparently healthy before death. Other authors have also reported similar experiences. ${ }^{23}$ While premortem diagnosis of invasive aspergillosis has been refined by new investigative techniques, ${ }^{4}$ it is still more often diagnosed at necropsy, ${ }^{1}$ and we reaffirm the value of necropsy in clinical audit. ${ }^{5}$

WH SHEK
KL CHAN
ISC LUK
Department of Pathology,
University of Hong Kong,
Queen Mary Hospital,
Hong Kong

1 Boon AP, O'Brien D, Adams DH. Ten year review of invasive aspergillosis detected at necropsy. J Clin Pathol 1991;44:452-4.

2 Hovenden JL, Nicklasson F, Barnes RA. Invasive pulmonary aspergillosis in immunocompromised patients. $B M J$ 1991;302:583-4.

3 Park GR, Drummond GB, Lamb D, et al. Disseminated aspergillosis occurring in patients with respiratory, renal and hepatic failure. Lancet 1982;ii:179-83.

4 Rogers TR, Haynes KA, Barnes RA. Value of antigen detection in predicting invasive pulantigen detection in predicting invasive pul-
monary aspergillosis. Lancet 1990;336: monary

5 Reid WA, Harkin PJR, Jack AS. Continual audit of clinical diagnostic accuracy by computer: a study of 592 autopsy cases. J Pathol 1987;153;99-107.

Costing of pathology services in the United Kingdom National Health Service

Professor Dick's useful review ended with a strong recommendation to pathologists to ensure they have "efficient resource management systems".' I cannot think how pathologists in the United Kingdom at present could disagree, but have a question and a comment.
The question is "who pays?"-that is, for the testing, introduction, and regular use of an efficient system.

The comment is that it is now vital that we pathologists give the same care and attention to obtaining and checking financial data about our laboratories, as most of us have for many years, to information about the number and variety of tests carried out and the quality of our results. In this department, however, the staff are very hard pressed to keep up with what, until now, has been regarded as their regular duties as clinical biochemists to provide results and comments to clinical colleagues, and it is hard to find the resources (staff) to assess, introduce, and apply simple computer packages for ordering, stock control, and noting expenditure without which accurate and precise budget statements can neither be obtained nor those from management validated.

A FLECK Charing Cross Hospital, Fulham Palace Road London W6 $8 R F$

1 Dick HM. Costing of pathology services in the United Kingdom National Health Service. J Clin Pathol 1991;44:705-9.

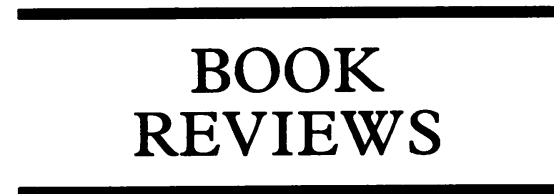

All titles reviewed here are available from the BMJ Bookshop, PO Box 295, London WC1H 9TE. Prices include postage in the United Kingdom and for members of the British Forces Overseas, but overseas customers should add $15 \%$ to the value of the order for postage and packing. Payment can be made by cheque in sterling drawn on a United Kingdom bank, or by credit card (Mastercard, Visa or American Express) stating card number, expiry date, and full name.

Surgical Pathology of the Female Reproductive System and Peritoneum. Ed SS Sternberg, SE Mills. (Pp 317; $\$ 102.00$ ). Raven Press. 1990. ISBN 0-88167726-4.

This short book, extracted from Diagnostic Surgical Pathology, covers the whole female genital tract, placenta, gestational trophoblastic disease and peritoneum in only eight chapters. It is not as detailed as the major diagnostic gynaecological text books, but the chapters are authoritative and comprehensively referenced up to 1990 . The text is clear with excellent monochrome and colour illustrations. Much of the content is familiar and represents a concise overview and updating of work presented in other textbooks. Hendrickson and Kempson's chapter on uterine pathology includes many of the charts and lists from their textbook. The three chapters which Young, Clement, and Scully have written on the ovary, fallopian tube, and peritoneum are excellent summaries and 
contain details of recently described lesions such as hepatoid ovarian carcinoma and the hepatoid variant of yolk sac tumour. Their contribution on the peritoneum gives good illustrated descriptions of benign lymph node inclusions of glandular, decidual, and smooth muscle tissue, endosalpingiosis and extra ovarian serous and mucinous lesions, which are not adequately covered in other text books. The chapter on the vulva and vagina includes the latest classification of vulvar dystrophies.

This book is insufficiently detailed across the range of subjects to be used as a diagnostic benchbook but it does give a convenient source of easy reference to recent developments. It represents good value for money and well suits the needs of doctors working for the MRCPath. I recommend it for the postgraduate or personal library.

LJR BROWN

A Guide to Infectious Diseases. MG Brook, MF McGhee. (Pp 236; soft cover £12.50). Radcliffe Medical Press. 1991. ISBN 1-870905-60-1.

This paperback was written by a senior registrar in infectious and tropical diseases and a general medical practitioner. Its aim is to be a concise up to date aide-mémoire suitable as a rapid reference on the more common and important infectious diseases for non-specialist hospital doctors, medical students, nurses and general practitioners. There are 17 chapters, beginning with one of four pages on epidemiology and public health aspects of infection, and continuing with chapters on infections of systems such as the central nervous system, heart, and so on. Chapter 10 on infections around the eye is well done and is followed by a concise chapter on the exanthemata, infection related rashes, and childhood infectious diseases. There is a good chapter on human immunodeficiency virus and its complications. The last four chapters describe infection in the traveller, fever of unknown origin, miscellaneous diseases, immunisation and preservation of health. The latter is a guide to the various vaccines and immunoglobulins available with their use and sources of supply.

There are three appendices comprising the current list of notifiable diseases, a list of infections with their incubation periods, and a table of vaccinations for foreign travel along the lines of the checklist in the Health Advice for Travellers from the Department of Health. The print is easy to read and the pages are laid out clearly with headings and subheadings for the short paragraphs, notes, and lists which make up the text. Overall, the book succeeds in its aims but I doubt whether readers of the Journal will wish to buy it. RN PEEL

Incidental Carcinoma of the Prostate. Ed JE Altwein, P Faul, W Schneider. (Pp 310; DM 118). Springer-Verlag. 1991. ISBN 3-540-53225-0.

The general pathologist in search of an update, seeing the title of this book, will want reassurance that there is guidance on how to make the diagnosis, the site and type of surgical specimens in which such lesions would be expected, and some insight into the general clinical relevance of the possible histological findings.

To what extent does the book fulfil a jaded, or a spritely trainee histopatholgist's needs? In fact, happily, most of the questions set above are answered beyond expectation. The only problem is how to thresh the wheat from the chaff. Naturally, other clinical specialties concerned with uropathology would make quite separate piles of wheat and chaff. It is true that there is a little chaff, but the answers to morphological diagnosis are given in Helpap's chapter, the site and relevant specimens are in Battaglia's and Schroder's, the general clinical relevance in Schulze's and many others. If you are even just passingly curious about prostatic diagnostic histopathology, this book is worth reading.

The book itself is arranged as a series of 41 articles. The hard-back binding, typography, illustrations and tables are presented to the exceptional high standard which has long characterised the publications of SpringerVerlag. Purchase for any diagnostic histopathology department involved in the routine assessment of prostates is recommended. The cost will not take long to justify itself.

JD DAVIES

\section{Some new titles}

The receipt of books is acknowledged, and this listing must be regarded as sufficient return for the courtesy of the sender. Books that appear to be of particular interest will be reviewed as space permits.

Drug Safety. A Shared Responsibility. (Pp 144; £9.95.) Churchill Livingstone 1991. ISBN 0443046557.

\section{NOTICES}

\section{ACP Locum Bureau}

The Association of Clinical Pathologists runs a locum bureau for consultant pathologists.

Applicants with the MRCPath who would like to do locums and anyone requiring a locum should contact The General Secretary, School of Biological Sciences, Falmer, Brighton, BN1 9QC. Tel and Fax: 0273678435

\begin{tabular}{|c|}
\hline $\begin{array}{c}\text { Fifth Workshop on } \\
\text { Gastroduodenal Pathology and } \\
\text { Helicobacter Pylori }\end{array}$ \\
Trinity College, Dublin, Ireland \\
6-7 July 1992 \\
Conference Secretariat: \\
CRUINNIU, 3 St Kevins Park, \\
Dartry, Dublin 6. \\
Telephone: $353-1-971710$. \\
Fax: $353-1-965983$.
\end{tabular}

Fifth Meeting and Workshop of the European Association for Haematopathology

21-25 September 1992

\section{Bologna, Italy}

The Meeting (21-23 September) will include a two day session devoted to the monocyte/macrophage system with special reference to the physiology, pathology, immunophenotyping and molecular genetics. The topic of the third day will be recent advances in haematopathology.

Fee: $410 \mathrm{DM}$

(or $470 \mathrm{DM}$ if paid after 29 February 1992).

The Workshop (24-25 September) will focus on the reactive and neoplastic proliferations of the monocyte/macrophage system.

Admission will depend on the submission of a case and on its selection by the panel of experts.

Fee: 170 DM

(to be paid before 31 May 1992).

The deadline for the submission of abstracts and cases is 29 February 1992. Further details are available from the EAHP local organiser: Professo Stafano Pileri, Emolinfopatologia, Istituto di Ematologia/II, Servizio di Anatomia Patologica, Via Massarenti 9, 40138 Bologna, Italy. Telephone: 3951-6364674. Fax: 39-51-388973); or from the organising secretariat: ICARIA, Via Zannoni 45, 40134 Bologna, Italy. Telephone: 39-51416690/410773. Fax: 39-51-421526.

VIIth International Symposium on the Biology of Vascular Cells

November 10-14, 1992

San Diego, California

The purpose of this meeting is to develop an accurate and current understanding of the role of vascular cells in biology and disease. This goal will be accomplished both through formal presentations and through an active informal discussion/social programme. This conference will be held at the Princess Resort located on a 44 acre island in San Digeo's Mission Bay.

For further information contact: Department of Academic Affairs, 403C Scripps Clinic and Research Foundation, $10666 \mathrm{~N}$. Torrey Pines Road, La Jolla, CA 92037. Telephone: (619) 554-8556.

\section{Correction}

An error appeared in the vertical axis to fig 2 of "Assessment of Diesse Ves-matic automated system for measuring erythrocyte sedimentation rate" by $M$ Caswell and J Stuart J Clin Pathol 1991;44:946-49. It should read, Junior Ves-tec and not Vaw-tec, as published. 